\title{
Value streams based strategy: modeling for lean management performance*
}

\author{
V. Cruz Machado ${ }^{\dagger}$, José Tavares \\ Department of Mechanical and Industrial Engineering, UNIDEMI, FCT University Nova of Lisboa, PORTUGAL
}

(Received November 6 2007, Accepted January 11 2008)

\begin{abstract}
This paper seeks to present a methodology to assess performance and to provide management decision support. A "management by value streams" model was developed to assess company performance. It was implemented to support decision-making at an industrial company. The idea behind the model is that products or services should continually flow in the organization, as values streams. The model includes a set of metrics to measure the level of achievements versus previous established organization strategic objectives. The approach aims to promote the spirit of continuous improvement and collaboration, breaking the individual and segmented logic of the traditional distribution of work. The model leads to the definition of two integrated performance indicators: the Process Sustainability Index and the Organization Performance Index. These indicators provide an analysis on the level of performance of existing value streams, as well as on the organization, as a whole. This analysis will contribute to identify new improvement opportunities. The paper concludes that the model helps the implementation process of the organization strategy deployment: it works as an invaluable tool to act and to promote communication at the several organization levels.
\end{abstract}

Keywords: value stream management, lean manufacturing, performance management, management by processes

\section{Introduction}

Processes transform material into products or services. More generally, a process can include a set of interrelated and interactive activities that transform inputs in outputs. Some activities, namely operations, are considered to add value, but processes also include non-value adding activities. A value stream consists of value and non-value adding activities that makes the transformation possible. It appears to be a simple concept, but in real situations, hundreds of processes can coexist under the same organization, to contribute to the value stream. Processes must be associated to organization objectives; they should be measured and goals should be defined. Each process will provide quantified results (namely, quantities, deliveries, lead times, etc.), that add some form of value to the customer (internal or external). In general, they can be considered as management processes, even if they integrate technological sub-processes. Usually, processes are organized in hierarchical modes; they can represent a value chain/business area/product family, or just elementary product handling or invoice processes.

Managing processes requires some important changes in an organizational structure. Even admitting that processes have been redesigned and simplified, the organization should address specific procedures to assure superior performance. Managing by processes based on value streams, as opposed to functional management, can provide a focused management system; the analysis and control of each value stream (or primary process) provides important benefits for the organization. However, the level of complexity, to manage so many different processes, requires specific studies and research on how to design new organizations.

\footnotetext{
* Authors would like to acknowledge Unidemi and Fundação para a Ciênciae Tecnologia.

${ }^{\dagger}$ Corresponding author. Tel: +86-28-85406958; E-mail address: vcm@ @ct.unl.pt.
} 


\section{Methodology}

A case study methodology was adopted for the study. A beverage business industry company was selected to provide data and to test the methodology. The case study will not be presented because of being lack of space.

\section{Performance evaluation}

Performance evaluation has been largely discussed ${ }^{[2,7,17]}$. Saad ${ }^{[16]}$ considers "Performance evaluation is perhaps the most powerful management tool for strategic deployment in both private and public settings". This situation results from the high competition environment. Opening the economy to new markets allowed a growing demand for information by managers and practitioners. The highly dynamic environment has forced the companies to adjust to the market change and introduce new management practices. Intangible assets became as important as the efficient use of the physical tangible assets. According to Porter ${ }^{[13]}$, the capacity of innovation, the loyalty of the customers, the flexibility, the performance and people motivation, became some of the main sources to achieve competition advantage and survival for the organization. Gone were the times when to manage the business, the main requirement was the analysis of the past. Today, the main point is to anticipate the future.

The higher the need of predictable and non-predictable changes is for the organization, the higher is the need for evaluating performance. Indeed, if we do not know where we are, we will not be able to define objectives, or even worse, to find the means to achieve them. Models for performance evaluation have been enriched to accommodate actual requirements and they are becoming a vital tool for managers.

The evolution of the models for performance evaluation has been related with the competitive variables that were recognized as important to be measured. Previous models were mainly oriented to financial measures ${ }^{[3,8]}$; these became inadequate as the information provided was very narrow. In a more advanced stage, the enterprises implemented financial and non-financial measures: financial measures were implemented to provide business control and were used by the organization upper management; non-financial measures were mainly implemented at the lower levels of the organization to control production. The natural evolution of performance evaluation models led to the integrated implementation of financials and nonfinancials measures for all hierarchy at the enterprise ${ }^{[15]}$. Top management tend to discontinue the exclusive implementation of financials measures, which show the results of the decisions made, and started to put in place non-financials measures as well. According to Anthony and Govindaragan ${ }^{[1]}$, non-financials measures are in line with the leading indicators of future performance; in addition, the lower level workers of the organization, started to understand the financial impact of their operating decisions.

Models for performance evaluation, as well as the criteria on which they are based, have undergone different stages of improvement to adjust to the present reality. Drucker ${ }^{[12]}$ considered five issues to evaluate the enterprise: 1 . Situation of the market; 2 . Innovation degree; 3 . Productivity; 4. Solvability (by the analysis of the cash-flow), and; 5. Profitability. For Kaplan and Norton ${ }^{[9]}$, the system to evaluate performance should contemplate, at least, four aspects: 1 . financial; 2. customers; 3. training, and; 4. growth. The analysis of these areas and the definition of the respective performance indexes, may allow the analysis of performance at the organization. This approach contemplates indexes of performance and indexes to determine the results: the former try to evaluate the vectors of performance that will lead to the achievement of results in the future; the latter reflect the results obtained from the measures implemented in the past.

Govindarajan et al..$^{[4]}$, and Sussland ${ }^{[19]}$, like Kaplan and Norton, point out the importance of performance evaluation to implement the strategy of the enterprise. The critical aspects of the day-to-day or future success of the enterprise should be identified and deeply analyzed, to define the strategy the enterprise wishes to develop. This point of view is reinforced by Lebas ${ }^{[10]}$ who considers that the objectives should be defined and discussed by top management with the involvement of the project managing team. Attention should be paid to the present situation of the enterprise and the future goals, reflecting the cause-effect relation that will be the basis of discussion to support continued improvement and decisions to be made. From the various advantages of performance evaluation, we point out the most relevant, presented by Kaplan et al. ${ }^{[9]}$ : 
- Wider participation and involvement of all intervenient,

- Leads to internal responsibility,

- Better communication between the hierarchies of the company,

- Increase the information flow,

- Better efficiency and productivity,

- Continued improvement,

- Supports strategy implementation,

- Leads to strategic alignment.

Other more traditional models of performance evaluation revealed to be inadequate $\mathrm{e}^{[3,8]}$. In fact, they only consider functional performance, i.e., the level of performance of a department or a given job by itself. This philosophy is a consequence of the old work division under which the company was organized according to the hierarchy of responsibilities. Such vision is limited within the overall organization, allowing some local earnings (at a department) in detriment of the global earnings within the organization. In fact, this situation results from the fact that business or activities have been systematically managed by a Functional Structure. Notwithstanding, the products and services have been produced and made available to the markets and clients, by business processes transversal to the Functions.

Due to the present day high competition, companies have to adjust themselves in terms of organizational procedures. Nowadays, the companies' main concern is related with organizing their activities by processes $^{[8,11]}$. In this context, the traditional vision to organize work has been questioned. This is a consequence of the growing perception that, despite the fact that most enterprises are organized under a functional perspective, their Processes are horizontally developed (see Fig. 1) crossing the different departments. The focus becomes on the optimization of the processes and activities, in detriment of the specialization that occurs in a functional vision. For Hammer et al. ${ }^{[5]}$, the processes correspond to work and information chains that cut the business horizontally and allow direct contact with the clients. In this context, management by processes

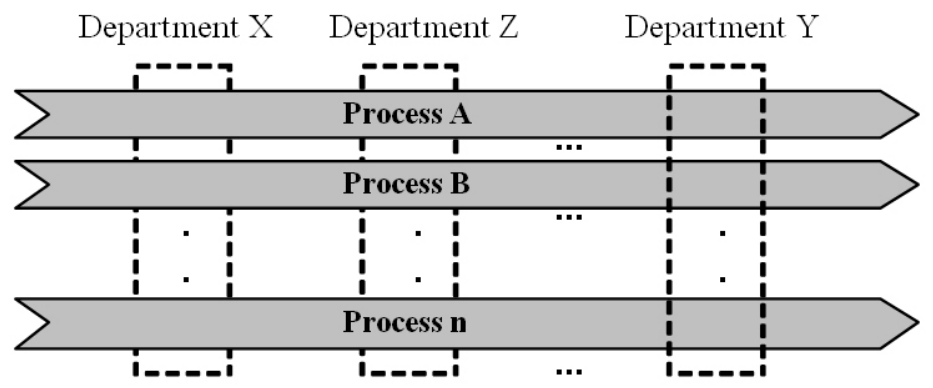

Fig. 1. Flux of processes

has become progressively popular, and is becoming a philosophy for the times ahead. The client is focused on the way the product or service is delivered to him, rather than on the organization of the enterprise or the management philosophy implemented. In other words, we can say that the client perceives the result of the internal process developed.

\section{Modeling performance}

Modeling management based processes systems are centered in the essential issue of performance evaluation: How can an organization implement its objectives and add value to the interested parties? The answer to this question should make the organization (re)consider its objectives and identify the best way to achieve them.

The model developed for performance evaluation considers that the success of each organization depends on the way their activities are developed. These activities are interconnected by a network of processes which cross different functional units and, eventually, the borders of the organization. The success of an enterprise 
may be measured by the results achieved on the implementation of a process that contributes to add value. Consequently, the organization should be seen as an open system, in permanent contact with the environment of which it is part of. Its performance depends on the way it develops the internal performance and the relation with the different external factors (see Fig. 2). This view is reinforced by $\mathrm{Yeo}^{[15]}$; he considers that the success of any enterprise depends on the balance between the individual and the entities with whom he deals, on a day-to-day basis, contributing in a direct or indirect manner to the development of their activities. In addi-

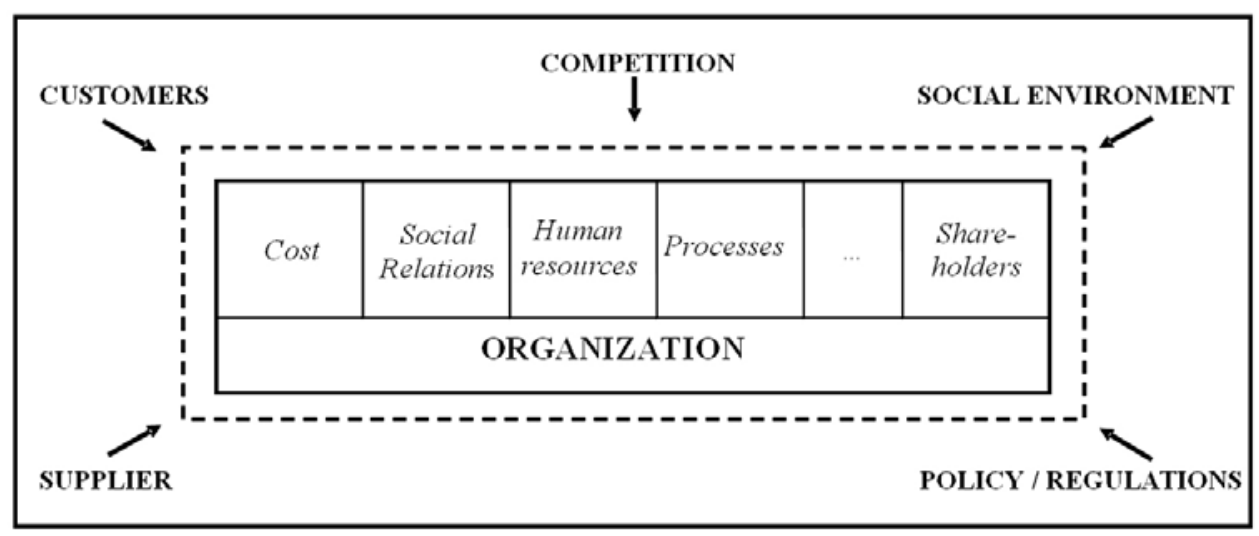

Fig. 2. Factors that interact with the company

tion, a company can be externally affected by five main factors (Fig. 2): 1. Customers; 2. Suppliers; 3. Social environment; 4. Policy/regulations and; 5. Competition. It is fundamental that internally the company establishes strong links with its workers as well as with shareholders, who wish to add value to their investment. To identify all the stakeholders of the company is an important step to develop the performance evaluation model.

\subsection{Model operation}

The model includes five main stages: 1 . the identification of critical processes; 2 . the implementation of a management by processes approach; 3 . the implementation of a process monitoring system; 4 . the development of improvement plans, and; 5. the implementation and control of action plans. A generic model overview is presented in Fig. 3. Based on the mission/vision of the organization and considering the strategic macro-objectives to be achieved, i.e., the main guidelines the enterprise wants to reach, the key factors that actually contribute to the success of the organization are defined. The key factors for the success of the enterprise should be identified by a multi-disciplined team, who should search the answer to the question: Which are the main requirements to implement the strategic macro-objectives of the organization?

When the key success factors are identified, the processes to support these factors, which add value to the organization, are checked. As a method to identify critical processes, the following factors should be considered $^{[9,17,19]}$ :

- Importance of the mission accomplishment,

- Key points for product quality,

- Direct contact with the clients,

- Key points for the success of business/activities,

- Macro or global approach,

- To cross several organization functions,

- Multidiscipline,

- Measurable and integrate the business plan,

- $\quad$ Begin and end with the client. 


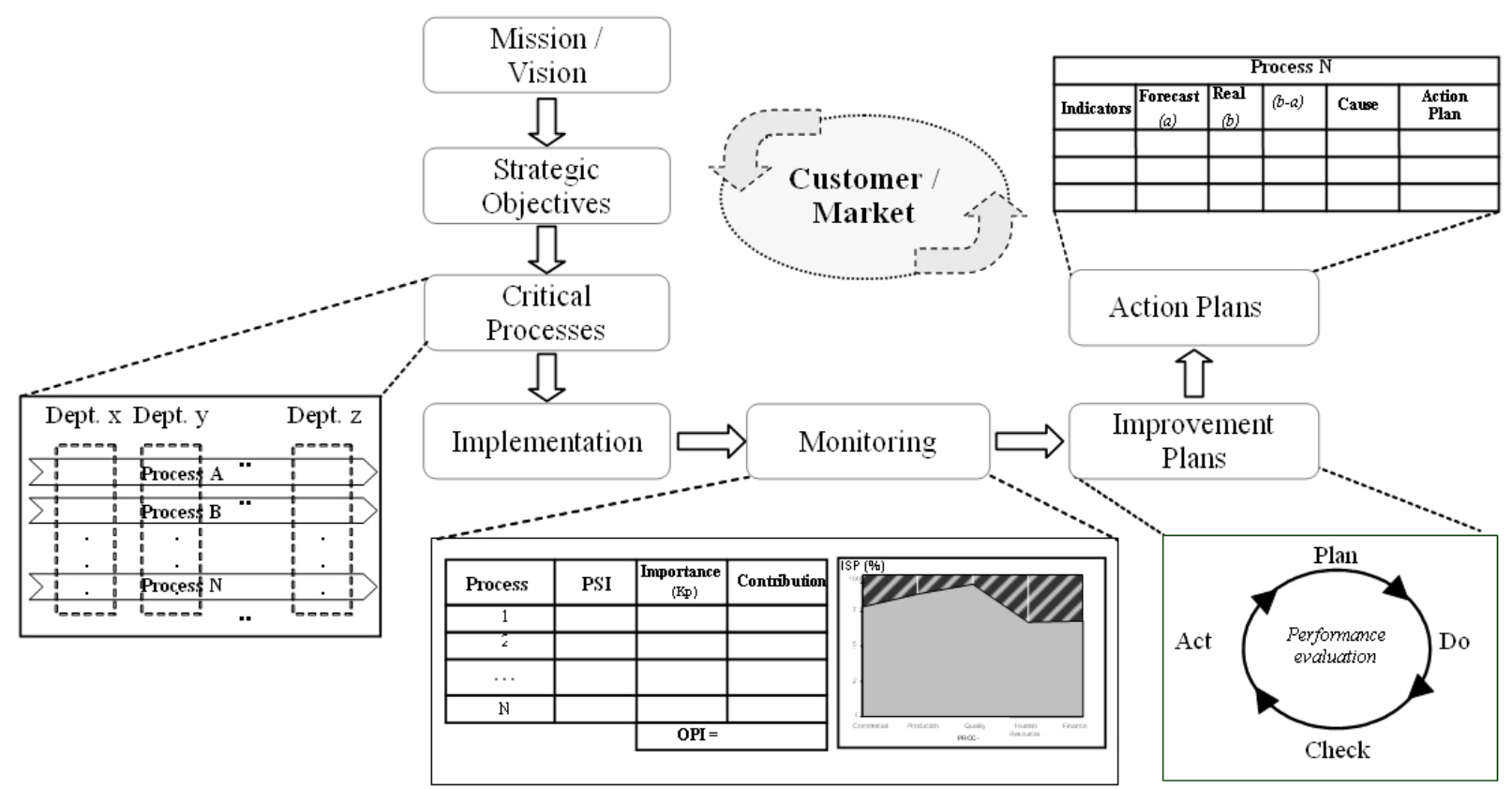

Fig. 3. The model cycle operation

For each process new indexes to evaluate the performance should be defined. These will be associated with the objectives to be achieved, which should be established before hand and will be used as a reference for later evaluation. The performance indexes to be considered should comply with the following rules:

a) To be established in accordance with the organization objectives, which should be directly related to its strategy,

b) To be established taking into account the consensus among individuals involved in different processes,

c) To be relevant for the analysis that will be made.

To establish the performance indicators one should consider the life cycle of the company. It is reasonable that the objectives of an organization in the starting up phase differ from those of an organization in the phase of growth or even maturity. Therefore, the performance indicators will also be different for each one of them. Each indicator should enable two different analyses (see Tab. 1):

Table 1. Reading of the performance indicator

\begin{tabular}{c|c|c|c}
\hline & Type of reading & Characteristics & Formula \\
\hline \multirow{2}{*}{ Indicator } & Action & Achievement vs. Estimate & $X_{i}=($ Real/Prevision $)$ \\
\cline { 2 - 4 } & Tendency & Evolution vs. Previous Period & $Y_{i}=N /(N-1)$ \\
\hline
\end{tabular}

- One against the established objective, by the comparison between what was anticipated and the actual achievement - Action Indicator,

- Another one related with the evolution of the indicator itself throughout the time, by the comparison against the previous period - Tendency Indicator.

Tab. 1 presents a general expression of each indicator, where $\mathrm{N}$ corresponds to the period being analyzed and $N-1$ the previous period. This analysis allows an improved understanding about the way the objectives are being accomplished.

Regarding the calculation of the financial data, a reliable and strict criterion should be followed to avoid jeopardizing the true picture or endanger its use in the context of the performance evaluation model itself. For that reason, the Cost calculation Based on the Activities (CBA) may be a better reliable option because of the precision it introduces in this type of analysis. 
Using CBA analysis as a tool to support the model for performance evaluation has proved to be an advantage ${ }^{[6]}$. This tool enables the definition of prices for products, the product-mix and the new products design and development. Another advantage is that the CBA can be a relevant tool to help decision making at a strategic level ${ }^{[4]}$. Just as Porter ${ }^{[14]}$ identifies the main competencies of the companies (core competencies), the CBA enables the identification of the main activities (core activities), as well as the activities of support (support activities). The first contributes directly to the company's mission or organization unit, while the second supports the development of the main activities of the company or even the business process. The CBA adds value and its potential is explored in the model developed.

Performance measurement is proposed to be calculated for each variable taking into account the following characteristics:

- A well defined method of calculation with clear and well known objectives,

- A guarantee of continuity to allow comparisons to show its tendency,

- To be based on ratios,

- To assure objectivity and coherence,

- To be reliable and credible,

- An exclusive financial character should not be assumed,

- To be simple and easy to use,

- To enable an easy and unmistakable reading and interpretation.

The performance monitoring will be made by the comparison between the objectives and their level of implementation. When the results are not in line with the objectives, the deviations should be calculated and the causes identified. The use of a PDCA-Plan, Do, Check, Act based on the Deming Cycle ${ }^{[18]}$, is a methodology proposed to promote the spirit of continued improvement; it will lead to the definition of an improvement plan. This will become the action plan that will provide the organization the means to achieve the established objectives.

\subsection{Integrated indexes and organizational performance}

For a global and integrated performance analysis two indexes were defined: the first is related to the process performance and it was designated as Process Sustainability Index (PSI); the second is related to the global performance of the organization and it was designated as Organization Performance Index (OPI).

The Process Sustainability Index is calculated for each process and its objective is to identify the performance level achieved. The PSI logic is based on the principle that a process is a group of different activities; some of these activities are developed under the direct leadership of distinctive areas or departments. Therefore, all the departments/areas (that are involved in a specific process) have to develop their jobs taking into consideration the global established objectives. In this way, the logic of the department is broken; instead, the individual contribution for the global success of the organization is developed.

Each performance index is associated to a weighted coefficient $K_{i}$, which is between the interval $0<K i_{\leq}$. It corresponds to the importance of this variable for the development of the global objectives of the process. The sum of all coefficients for a given Process should make a unit. The contribution of each performance indicator for the PSI calculation should be made resorting to the appraisal of the expressions (1) and (2), regarding each situation described:

(i) The performance indicator is below the objective;

$$
\text { PSI }=\left[\frac{\text { Real }_{A}}{\text { forecast }_{A}}\right] \times K_{i A} \times 100
$$

(ii) The performance indicator is above the objective;

$$
\text { PSI }=1+\left[1-\frac{\text { Real }_{A}}{\text { forecast }_{A}}\right] \times K_{i A} \times 100
$$


The objective for this indicator is to define the global performance of the organization with basis on the different process. The OPI is based on the logic that the success of an enterprise is straight connected with the manner the processes are implemented.

Each Process should be associated to a coefficient of pond ration $\left(K_{p}\right)$ which is between the interval: $0<K_{p} \leq 1$. The definition of this coefficient depends on the particular contribution of each process to the development of the global objectives of the organization. The sum of the different $K_{p}$ defined for the set of the different process should make a unit.

The OPI is calculated, as follows:

$$
\text { OPI }=\left[\left(\operatorname{ISP}_{1} \times K_{p 1}+\ldots+\operatorname{ISP}_{n} \times K_{p n}\right)\right] \times 100
$$

The companies can define objectives for the Organizational Performance Index by establishing a target to strengthen the performance and involvement between the various parties in the process. Since OPI is presented in terms of percentage, obviously, the ideal result would correspond to $100 \%$.

However, the objectives should be structured for a length of time and, many times, can only be achieved in a progressive form. Yet, they should be developed and supported by the knowledge that the company has about the processes. The analysis of the two indexes assumes particular relevance if the same pond ration coefficient is maintained for a period of time, to enable comparisons that can show the evolution of each variable.

The Organization Performance Graphic is prepared using the different indicators that characterize the process. This allows the identification of the gap between the achievements and the objectives (see Fig. 4-in this graphic the vertical axis corresponds to the percentage of the performance of each process, whereas the horizontal axis represents the contribution of each functional area to the different processes at the organization). Since the companies' main concern is to maximize their objectives, the graphic showing organizational

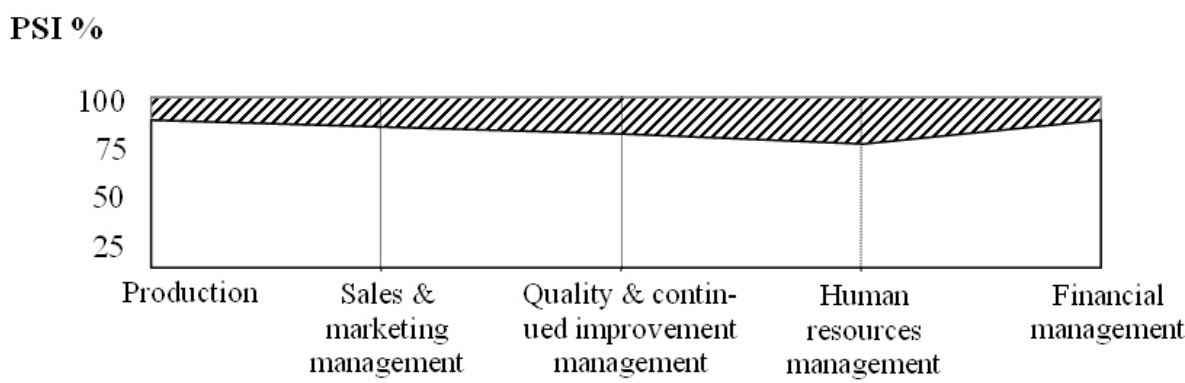

Fig. 4. The model cycle operation

performance should be as close to $100 \%$ as possible. The higher value corresponds to the better achievement of the objectives and consequently, the global performance of the company.

Having established the level of achievement for each indicator, the next stage consists on the analysis and interpretation of the results obtained. This can be achieved by the construction of an Action Plan Matrix. This matrix (Tab. 2) must be prepared for each process and highlight the deviation of the results obtained for each performance indicator. For each deviation that occurs, the respective cause should be indicated and a

Table 2. Action plan matrix

\begin{tabular}{c|l|l|l|l|l}
\hline \multicolumn{5}{c}{ Process / Value Stream } \\
\hline Indicator & Forecast $(a)$ & Real $(b)$ & Difference $(b-a)$ & Reason for the difference & Action Plan \\
\hline 1 & & & & & \\
\hline 2 & & & & & \\
\hline$\ldots$ & & & & & \\
\hline $\mathrm{n}$ & & & & & \\
\hline
\end{tabular}

definition of an action plan should be set, to allow the recovery of an eventual negative result. 
The model acts as a tool in the implementation of the organization strategy. The reason is that the key factors to achieve success are based on strategic objectives of the organization, which are directly connected to the indicators and metrics used. The systematic monitoring of these indicators will provide real time feedback to adjust the processes to the strategic objectives.

\subsection{Model implementation}

The implementation of the model requires a deep understanding of "process management" and "management by processes". Process management can be achieved within an organization when there is a specific orientation for the process; in addition, it should provide satisfaction to the customer that receives the out-put of that process. However, management by processes means that there is a management based process system able to manage all the activities of the organization as an integrated system to deliver the right output (products and services) to customers.

The implementation requires important cultural and organizational changes in the way organizations are managed. Consequently, the proposed model and its implementation should address the following requirements:

- Identification of organization needs and objectives - the aim of the model application, as well as its extension (to a specific area or the overall organization) must be defined and communicated to all the people involved in the organization. The actual performance evaluation system should be assessed and eventually new (strategic and operational) objectives should be formulated.

- Definition of critical success factors-the identification of these factors will clarify the role of each process to provide increased value-added to customers.

- Identification of critical processes - these processes must be clear for everyone in the organization, as any problem can cause dissatisfaction and can put the organization in a dangerous position; they provide the success to the critical factors identified in the previous step.

- Definition of indicators and metrics-indicators must reflect on how the critical processes are being performed to reach the organization strategic objectives. The number of indicators must be designed to provide the adequate level of information; the decision support system should be based on essential (and not redundant) data.

- Definition of coefficients and weights $-K_{i}$ and $K_{p}$ should be tested to assure its adherence to the model and organization objectives.

- Final parameterization and presentation-timing, periodicity and data sources should be defined and maintained throughout the evaluation cycles.

\section{Conclusions}

Modeling a management based processes system is a complex but rewarding project; the model developed for performance evaluation revealed interesting results, with positive trends. Depending on the indicators selected, the model can provide a better understanding on the processes under analysis. The role and contribution of each individual (department or person) for the global results of the organization can be drawn and; and, eventually, an improvement plan can be designed and implemented.

In addition, the model revealed to provide benefits in a number of areas, namely:

- Monitoring and follow up the evolution of the main parameters that affect the organization success, providing management focus on the main processes,

- Helping to implement the strategy,

- Encouraging the spirit of the management team,

- Leading to the involvement and participation of people,

- It outlines opportunities for improvement,

- Leading to the continued improvement,

- The use of financials and non-financials indicators allows to focus on the result of the decisions made and to anticipate the future performance, 
- Leading to responsibility,

- Leading to the identification and assertion of the factors that go beyond the organization,

- Using integrated indicators enables a global vision of the organization performance, breaking the interfunctional barriers that are typical for most enterprises,

- Defining action plans makes the organization consider the requirements to achieve the objectives.

- It becomes a supporting tool when making decisions.

The easy utilization of this model and the results obtained, give the method a potential to be used in any kind of organizations. The end of the segmented logic and individual performance and the turn to the global performance vision, can be supported by the model of performance evaluation proposed; everyone can contribute to the final results of the organization. This topic provides an immediate challenge to the management team, aiming to improve the company in the medium and long term.

\section{References}

[1] R. Anthony, V. Govindarajan. Management Control Systems, 9th edn. Irwin/McGraw-Hill, New York, 1998.

[2] M. Bourne, M. Kennerley, M. Franco-Santos. Managing through measures: a study of impact on performance. Journal of Manufacturing Technology Management, 2005, 16(4): 373-395.

[3] P. Charles. Performance measurement. Work Study, 2000, 49(2): 63-66.

[4] V. Govindarajan, J. Shank. Strategic cost management, 1st edn. The Free Press, New York, 1993.

[5] M. Hammer, S. Stanton. How process enterprises really work. Harvard Business Review, 1999, 77(6): 108-118.

[6] J. Innes, F. Mitchell. A Practical Guide To Activity Based Costing. Kogan Page, London, 1998.

[7] P. Johnson, C. Cassell, etc. Performance evaluation and control: supporting organizational. Management Decision, 2001, 841-850.

[8] H. Jordan, C. Neves, A. Rodrigues. O controlo de gestoao servioda estratgiaedos gestores. 1999.

[9] R. Kaplan, D. Norton. Using the balanced scorecard as a strategic management system. Harvard Business Review, 1996, 75-85.

[10] J. Lebas. Performance measurement and performance management. International Journal of Production Economics, 1995, (41): 23-35.

[11] R. McAdam, D. McCormack. Integrating business processes for global alignment and supply chain management. Business Process Management Journal, 2001, 7(2): 113-130.

[12] D. Peter. Managing for the future. Butterworth-Heinemann Ltd, 1992.

[13] M. Porter. Competitive advantage. Free Press, 2004.

[14] M. Porter. Competitive Strategy: Techniques for Analyzing Industries and Competitors, 2004th edn. Free Press, 2004.

[15] Y. Roland. The tangibles and intangibles of organisational performance. Team Performance Man-agement: An International Journal, 2003, 9(7/8): 199-204.

[16] H. Saad. Strategic performance evaluation: descriptive and prescriptive analysis. Industrial Man-agement and Data Systems, 2001, (2): 390-399.

[17] J. Saenz. Human capital indicators, business performance and market-to-bock ratio. Journal of Intellectual Capital, 2005, 6(3): 374-384.

[18] W. Shewhart. Statistical method from the viewpoint of quality control. Dover Publications, New York, 1986.

[19] W. Sussland. Align your management processes for effectiveness. The TQM Magazine, 2003, 15(2): 108-116. 